\title{
Effects of Written Emotional Disclosure on the Stress of Mothers of Children with Autism
}

\author{
Mahsa Ebadi ${ }^{1}$, Marjan Mardani-Hamooleh ${ }^{2}$, Naima Seyedfatemi ${ }^{3}$, Mahnaz Ghaljeh ${ }^{4}$,
}

\author{
Shima Haghani ${ }^{5}$
}

\begin{abstract}
Background \& Aims: Autism spectrum disorder is a complex neurodevelopmental disorder whose clinical manifestations include impaired social communication, behaviors, interests, and limited and repetitive activities. Poor eye communication, lack of emotion or social interaction, impaired use of non-verbal behaviors, and lack of age-appropriate communication are the main manifestations of this disorder. This disorder is one of the main causes of disability in children under 5 years old. The exact cause of this disorder has not yet been determined, and it can often be diagnosed by comparing autistic children's speech and performance with those of their peers. In comparison to parents of typically functioning children or parents of children with other developmental disabilities (i.e. Down's syndrome or cerebral palsy), parents or caregivers of children with an autism spectrum disorder experience more parenting stress which makes its management imperative. Parenting stress in this group of women results in depression, anxiety, divorce, reduced family cohesion and physical health, more incidence of behavioral problems in the children, and problems related to parenting. Thus, it is imperative to identify effective methods that target improvement in caregivers' mental health.

The problems that mothers face in raising their children from an early age put a lot of pressure on parenting skills, and if the parents' understanding of the demands of their role is greater than the resources and methods available for coping with them, so that they will be unable to restore balance in the usual ways, it will lead to stress in parents. In the case of parents of children with autism, maternal stress is reported more than the paternal stress, and more than mothers of children with other developmental disorders and mothers of normal children. Therefore, given that the caregivers of (75\%) of children with autism are their mothers, it is not unbelievable that mothers of this group of children struggle with a lot of stress. Mothers of children with autism are their primary caregivers, leading to depression, anxiety, quitting job, and suicide. Thus, effective interventions to improve the mental health of caregivers of children with autism seem necessary and the need to improve their mental health is felt. However, the results of studies that have been done so far indicate that this emotional revelation intervention through writing has been inconsistent or even ineffective on the mental health of mothers of children with autism. This study aimed to evaluate the efficacy of written emotional disclosure in parenting stress of mothers with autistic children. Material \& Methods: In this study, conducted in 2019, a quasi-experimental design including pre-test, post-test, and control group was used. First, a sample size of 70 mothers with autistic children were selected and tested from the autistic schools in Tehran. In pre-test, the Parenting Stress Index-short form (PSI-SF) was administered individually to experimental group $(n=35)$ and control group $(n=35)$. Then, written emotional disclosure, at least 15 minutes, twice a week over an 8-week period was conducted in experimental group whereas the control group received no intervention. Three mothers in the experimental group withdrew from the study due to personal
\end{abstract}

\footnotetext{
1. Department of Psychiatric Nursing, Nursing Care Research Center, School of Nursing and Midwifery, Iran University of Medical Sciences, Tehran, Iran

2. Department of Psychiatric Nursing, Nursing Care Research Center, School of Nursing and Midwifery, Iran University of Medical Sciences, Tehran, Iran

3. Department of Psychiatric Nursing, Nursing Care Research Center, School of Nursing and Midwifery, Iran University of Medical Sciences, Tehran, Iran (Corresponding author) Tel: 021-43651722 Email: seyedfatemi.n@iums.ac.ir

4. Community Nursing Research Center, Department of Nursing Management at School of Nursing and Midwifery, Zahedan University of MedicalSciences, Zahedan, Iran

5. Biostatistics, Nursing Care Research Center, Iran University of Medical Sciences, Tehran, Iran
} 
reasons. Therefore, the study continued with 67 mothers. After the intervention, the parenting stress was measured again in both groups. In the intervention group, the mothers first wrote about their deepest feelings and negative experiences of caring for an autistic child. Topics for mothers to write about included their feelings when they found out their children were diagnosed with autism; writing down the most difficult situations they had experienced in communicating with their autistic children; the most important issues that had made them upset in their daily lives about their children; and what do they do when their children do not cooperate with them?

Ethical considerations of the research, including informed consent to participate in the research and obtaining consent from the participants, observing the principle of confidentiality and avoiding bias in announcing the results of the study, have been observed. Data were analyzed using descriptive statistics (mean and standard deviation) and inferential statistics (independent t-test and paired t-test) in SPSS 16.

Results: The results of independent t-test showed that there was no statistically significant difference between parenting stress of mothers $(\mathrm{P}=0.881)$ and its subscales $(\mathrm{P}<0.05)$ before the intervention, but after the intervention this difference was significant $(\mathrm{P}<0.001)$, so that in the experimental group, the scores of parenting distress were significantly lower than the control group but the scores of parenting stress of mothers and other subscales were significantly higher. The results of paired t-test showed that parenting stress of mothers and its subscales in the control group were not significantly different before the treatment and after the treatment $(\mathrm{P}$ $<0.05)$, but the scores of parenting distress after the intervention decreased significantly in the experimental group and parenting stress scores and its other subscales increased significantly ( $\mathrm{P}<0.001$ ). The results of independent t-test showed that the reduction of parenting stress scores of mothers and its subscales was less in the intervention group than the control group $(\mathrm{P}<0.001)$.

In addition, the independent and paired t-test analysis showed that written emotional disclosure was effective in reducing parenting distress sub-scale in experimental group $(29.06 \pm 6.01)(\mathrm{p}<0 / 001)$. Also, the intervention could not improve the scores of parenting stress among experimental group $(128.78 \pm 12.29)(\mathrm{p}<0.001)$.

Conclusion: Written emotional disclosure, as a useful therapeutic intervention could be effective in improving parenting distress sub-scale, but ineffective in improving parenting stress. The findings of this study could also reinforce the hypothesis that expressing positive emotions about chronic stress may lead to more adaptive functions. This study suffers from some limitations. It was conducted on limited number of mothers with autism children, the same gender, and therefore, its generalizability is reduced. The results of this study show that the intervention of written emotional disclosure has been effective in increasing parenting stress of mothers with autistic children. Therefore, it is recommended to perform this method under the supervision of a consultant to control its negative effects. It is also suggested that future research, in addition to examining the variables affecting the effectiveness of this intervention, standardize the intervention pattern in writing positive, negative, and neutral emotions and use more follow-up sessions to enable more comparison.

Keywords: Written Emotional Disclosure, Autism Spectrum Disorder, Parenting Stress

\section{Conflict of Interest: No}

How to Cite: Ebadi M, Mardani-Hamooleh M, Seyedfatemi N, Ghaljeh M, Haghani SH. Effects of Written Emotional Disclosure on the Stress of Mothers of Children with Autism. Iran Journal of Nursing. 2021; 34(131):19-30.

Received: 5 May 2021

Accepted: 7 Aug 2021 


\title{
تأثير آشكارسازى هيجانى از طريق نوشتن بر استرس ماداران كودكان مبتلا به اوتيسم
}

\author{
مهسا عبادى'، مرجان مردانى حموله'، نعيمه سيدفاطمى "، مهناز قلجهُ، شيما حقانى
}

جكيده

زمينه و هدف: مادران كودكان مبتلا به اوتي سم در مقاي سهه با مادران كودكان عادى يا مادران كودكان مبتلا به ساير اختلالات ر شدى، بيشتر در معرض ه ابتلاء به استرس مرتبط با نقش والدى هستند. هدف تحقيق حاضر، تعيين تأثير آشكارسازى هيجانى از طريق نوشتن بر استرس مادران كودكان مبتلا به

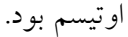

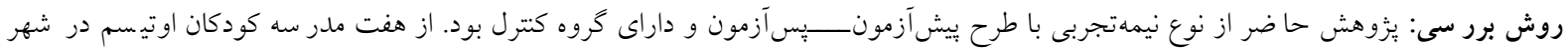

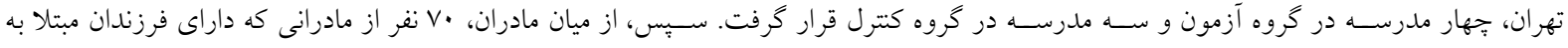

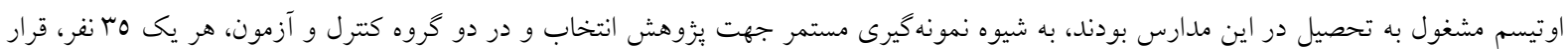

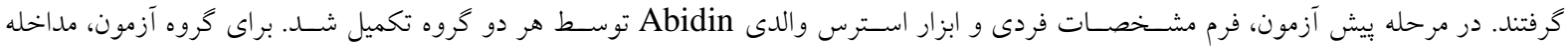

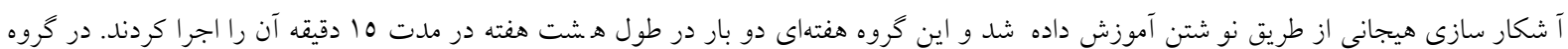

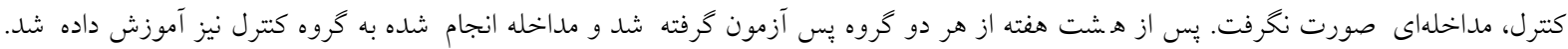

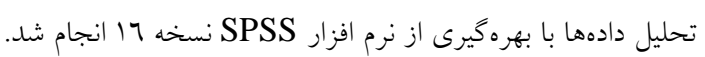

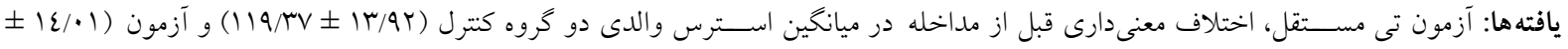
| (I/N/A)

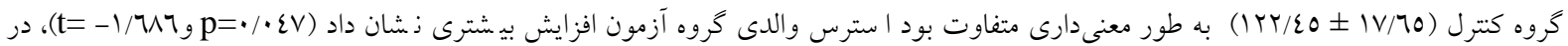

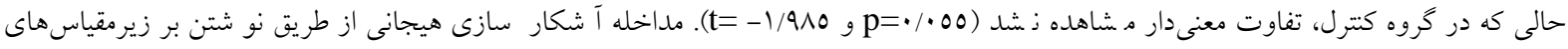

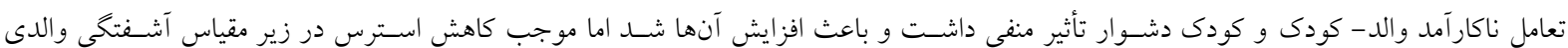
نتيجه گيرى كلى: از آن جا كه آ شكار سازى هيجانى از طريق نو شتن، استرس والدى مادران كودكان مبتلا به اوتي سم را افزايش داد، بي شنهاد مى شود

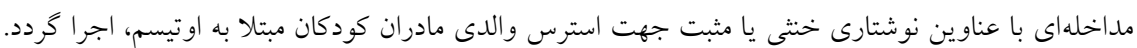
كليل وازهها: آشكار سازى هيجانى از طريق نوشتن، اختلال طيف اوتيسم، استرس والدى

$$
\begin{aligned}
& \text { تعارض منافع: ندارد }
\end{aligned}
$$

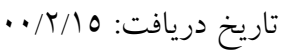

$$
\begin{aligned}
& \text { تاريخ يذيرش: 10/17/ . }
\end{aligned}
$$

' ' ترووه روانيرستارى، مر كز تحقيقات مراقبتهاى يرستارى، دانشكده يرستارى و مامايى، دانشكَاه علوم يزشكى و خدمات بهداشتى درمانى ايران، تهران، '. كروه روانبرستارى، مر كز تحقيقات مراقبتهاى يرستارى، دانشكده يرستارى و مامايى، دانشكاه علوم يزشكى و خدمات بهداشتى درمانى ايران، تهران،

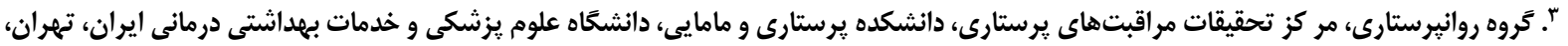

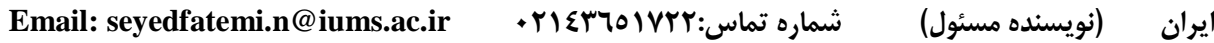

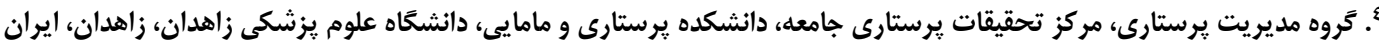

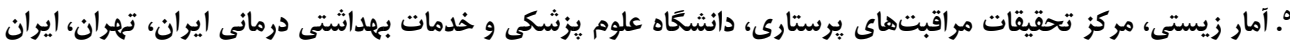


بيشــتر از والدين كودكان عادى و يا حتى والدين كودكان

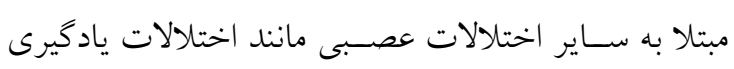
خاص، اختلالات ذهنى، سندرم داون، فلج مغزى و اختلال

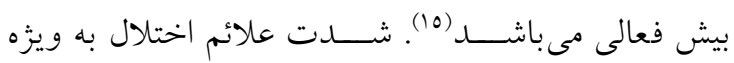

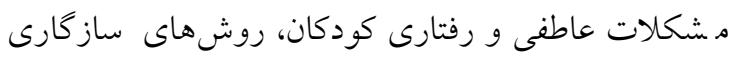

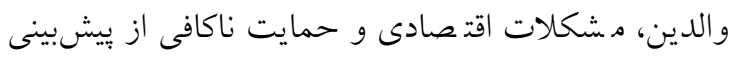

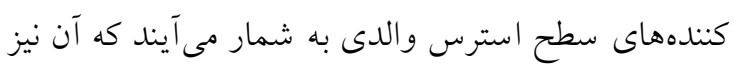
به نوبه خود منجر به افزايش مشــــاتلات رفتارى كودكان،

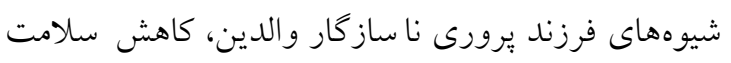
روانى، اختلال در اجراى مداخلات رفتارى كودكان و تأثير منفى روى سلامت والدين و كودى مىشود (17).

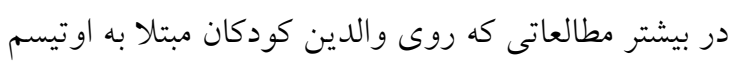

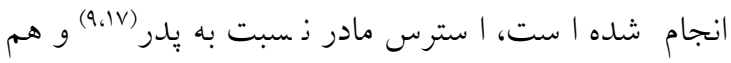

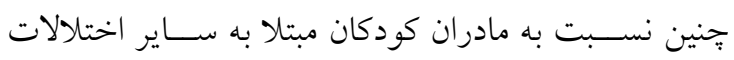

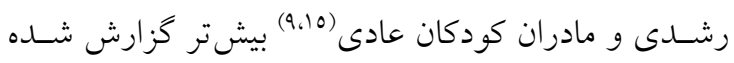

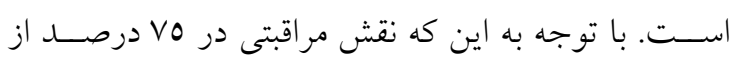

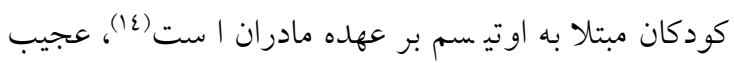

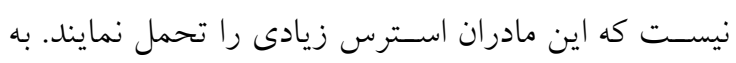

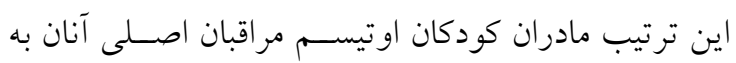

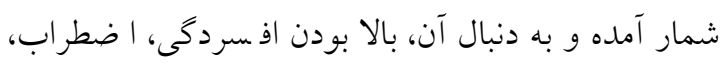

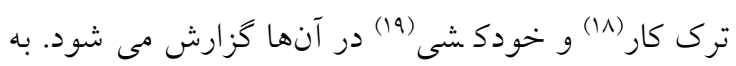

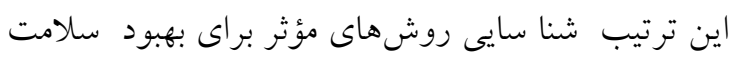

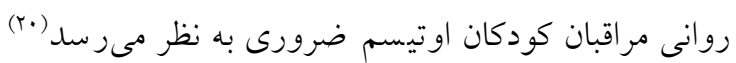

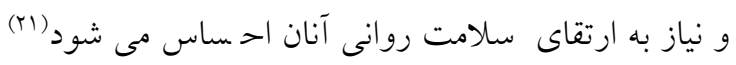

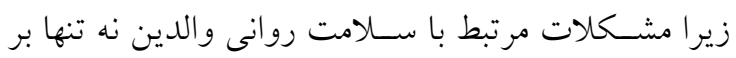

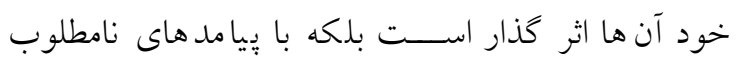

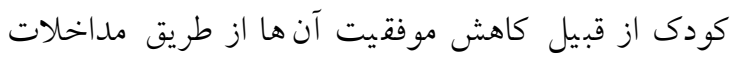

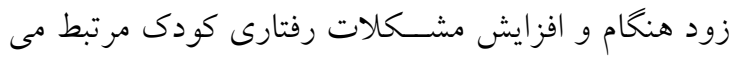

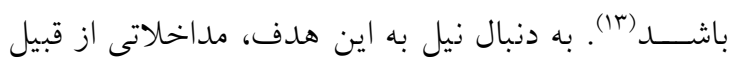
كاهش ا سترس مبتنى بر ذهن، روش آرام سازى و درمان

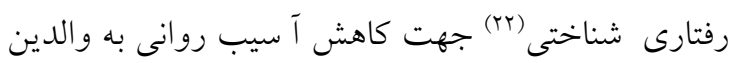

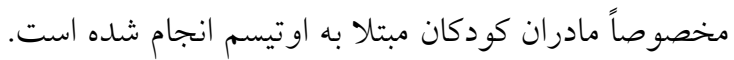

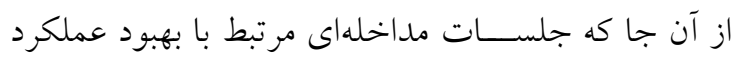

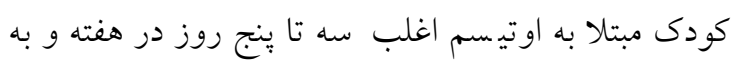

\section{مقدمه}

اختلال طيف اوتي سم يك اختلال يِّيجيده ع صبى ا ست (1)

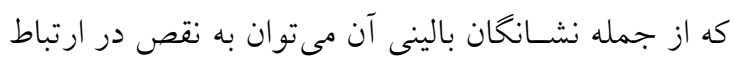

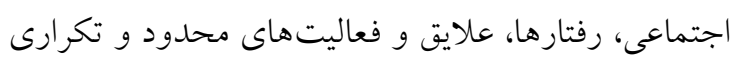

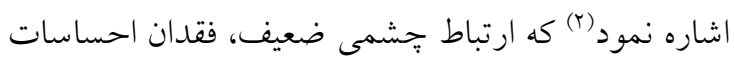

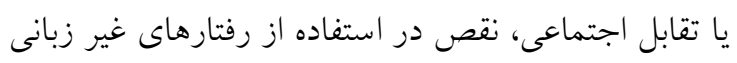

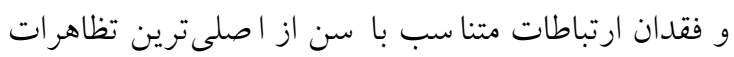

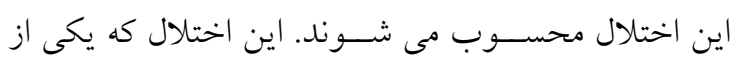

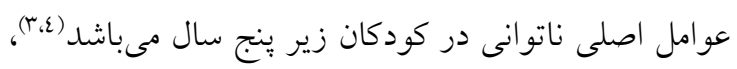

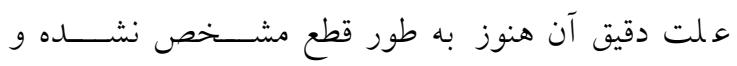

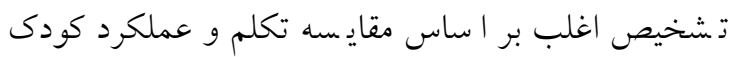

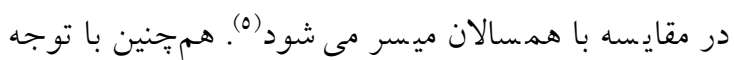

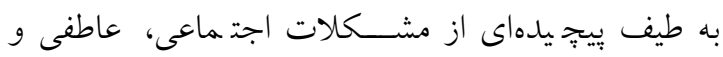

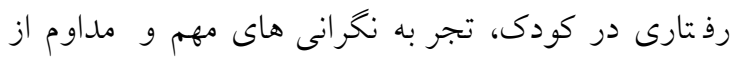

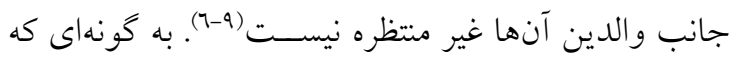

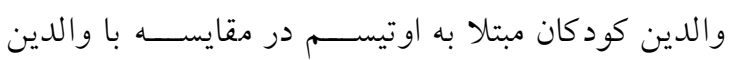

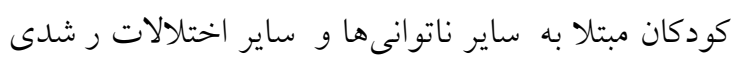

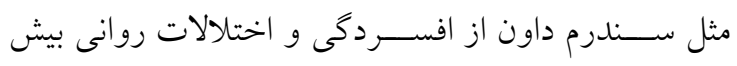
تر (1) و سلامت جسمى ضعيفترى (11) رنج مى برند.

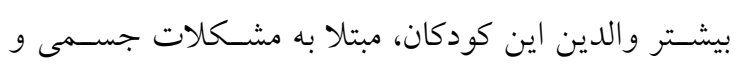

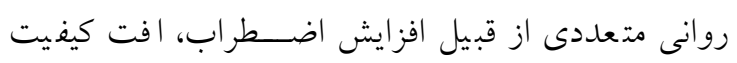

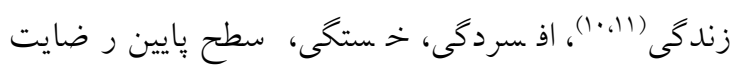

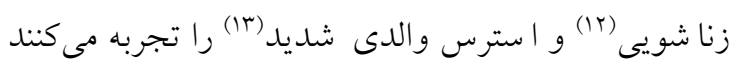

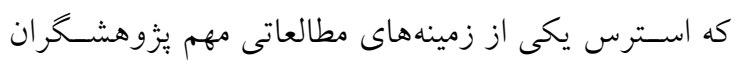

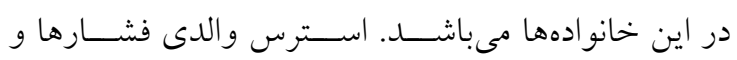
دشـــوارى هايى كه والدين در مراقبت از كودى و انجام

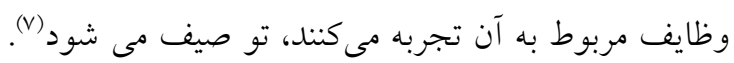

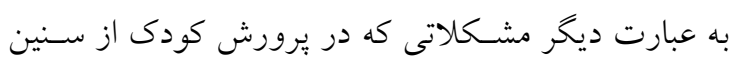

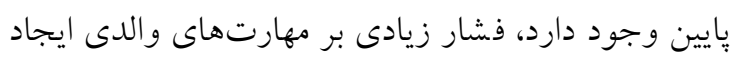

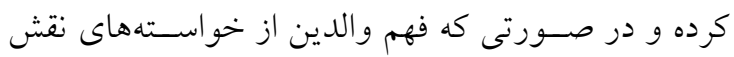

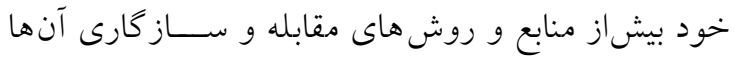

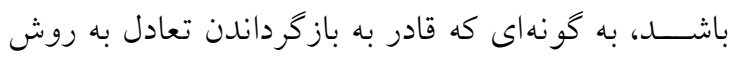

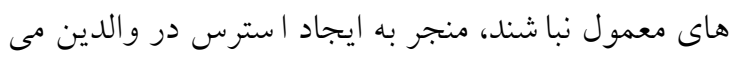
شود (ع). استرس والدى در والدين كودكان مبتلا به اوتيسم 
حاضر با هدف تعيين تؤثير آشكار سازى هيجانى از طريق

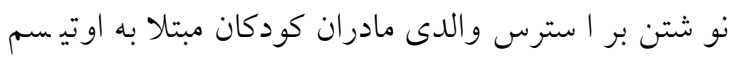

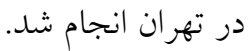

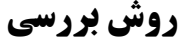

روش مطالعه حاضـر از نوع نيمه تجربى (ييش آزمون، بِ بس

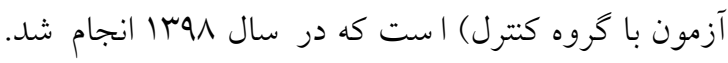
جامعه آمارى اين يزوهش تمام مادران داراى كودكان مبتلا

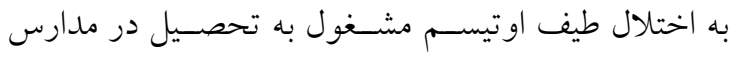

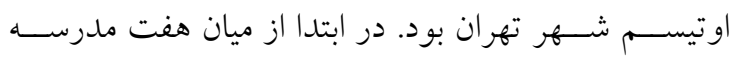
مختص اوتيسم در شهر تهران به صورت تصادفى ساده از

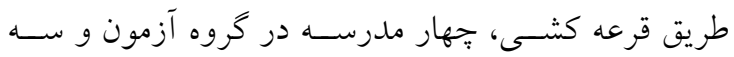
مدر سه در كروه كترل تقسيم شد سبس بعد از يك دوره جلب مشــاركت يكى ماهه در مدارس، تعداد •V نفر (ro)

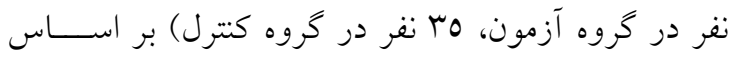
تقسـيمبدندى اذجام كرفته، در دو كروه آزمون و كتنترل

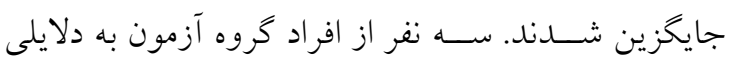
شـخصسى از مطالعه خارج شـــند. بر اين اسـاس، كروه

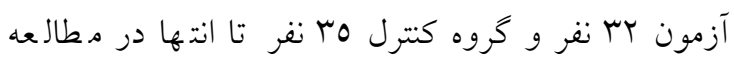
شركت داشتند. با توجه به اطمينان دادن به كروه كتترل كه

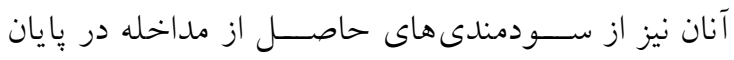

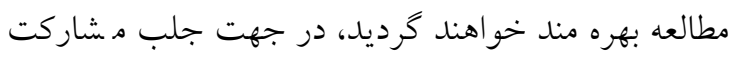

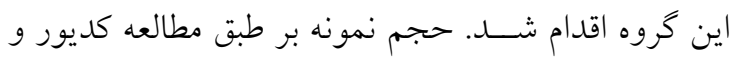

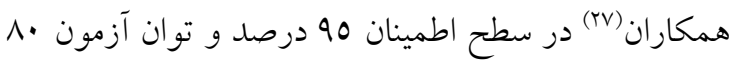
درصـــ و با فرض اين كه تأثير آشـكارســازى هيجانى از طريق نوشتن بر استرس مادران كودكان مبتلا به اوتيسم در

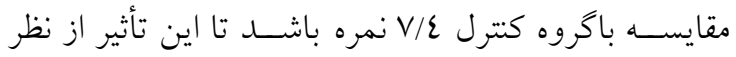

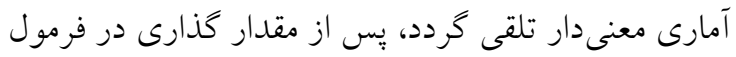

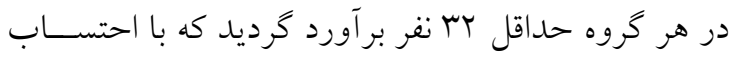
افت نمونه Oب نفر محاســبه شـــــ ملاكىها جهت ورود

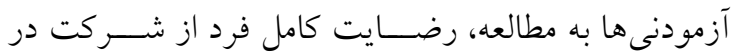

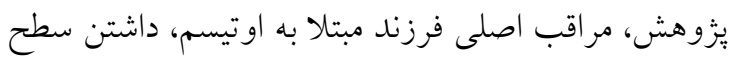
تحصيلات حداقل در حد خواندن و نوشتن، نداشتن اعتياد

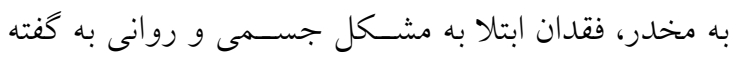

طور متو سط دو تا شش ساعت در روز به زمان نياز دارد

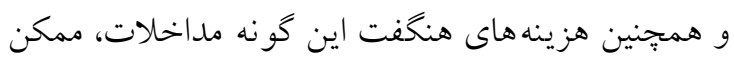

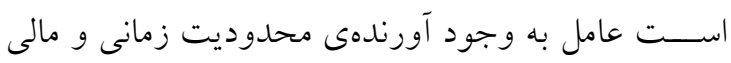
براى وا لدين به منظور ا قدام جهت در مان مان هاى رودان شناختى خود باشد (·). از طرفى بيشتر مداخلاتى كه با مشاركت مراقبتدهند ماندان

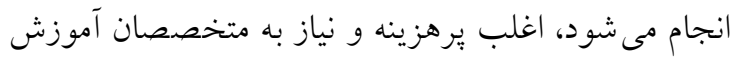
ديده دارد و به دنبال آن جلب مشـاركت آنها نيز به دلايل

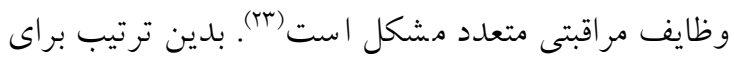

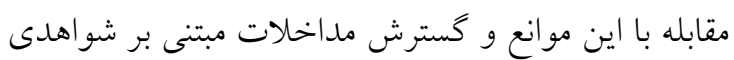

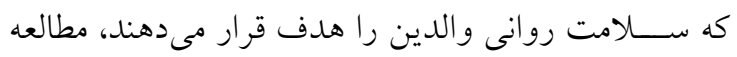

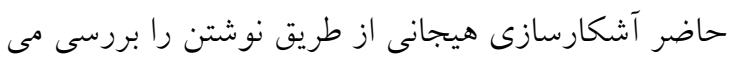

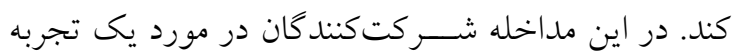

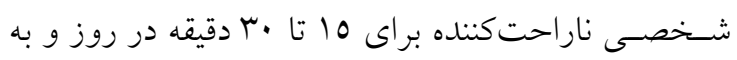

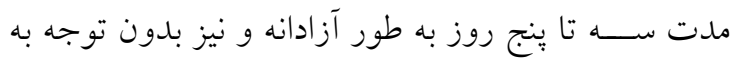

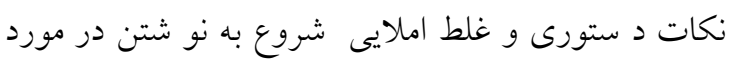

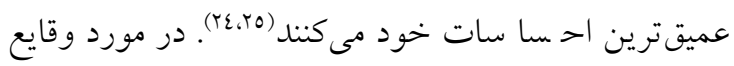

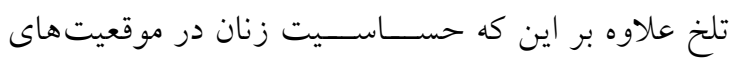

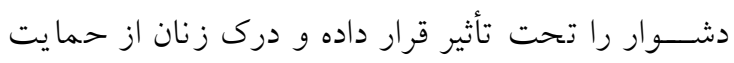

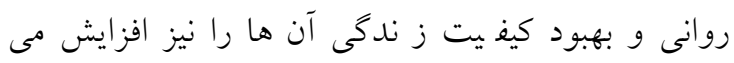

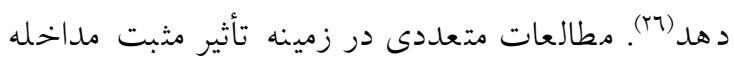
آ شكار سازى هيجانى از طريق نو شتن بر ا سترس مادران

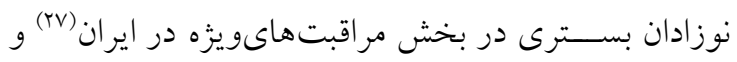

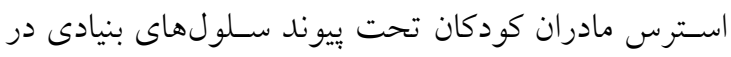

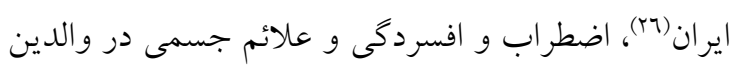

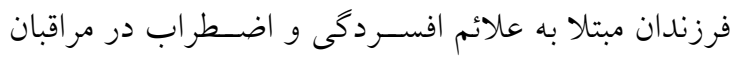
غير رسمى و استرس روان شناختى و فيزيولوزيك والدين

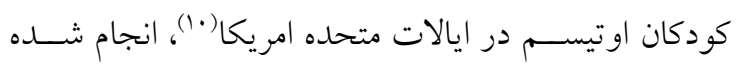

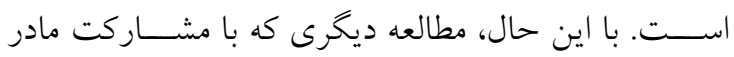
بزرگان كودكان در ايالات متحده امريكا انجام شـــــ بيانكر

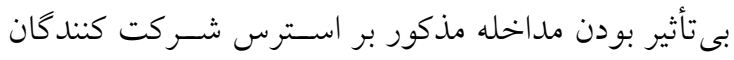

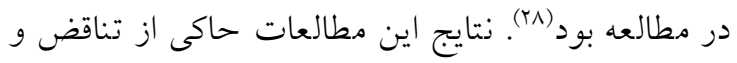

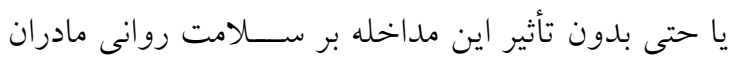

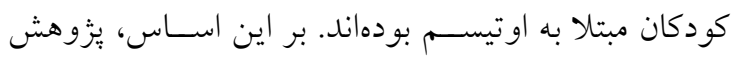


به مدت 10 دقيقه انجام دادند اما كروه كنترل هيج مداخله

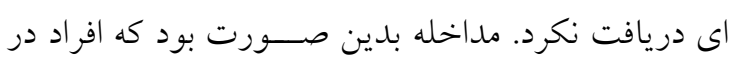

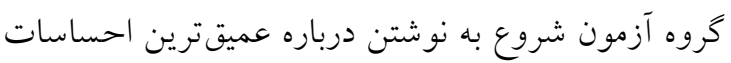

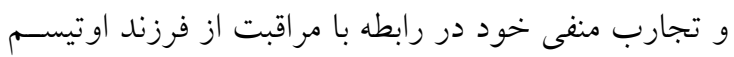

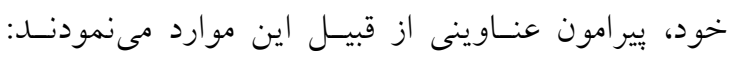

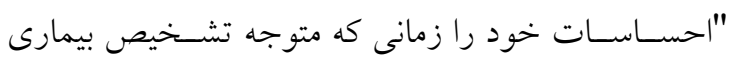
اوتيسم در فرزندتان شديد، بنويسيد. دشوارترين شرايطى را كه در برقرارى ارتباط با فرز ند خود تجر به كردها يد،

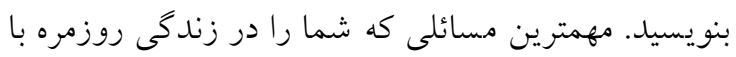
فرزندتان ناراحت مى كند; بنويسيد. وقتى فرزندتان با شما

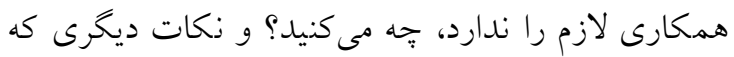

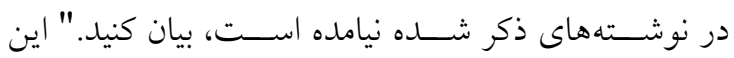

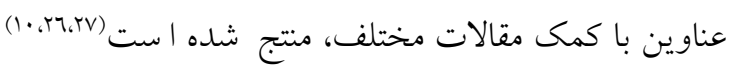

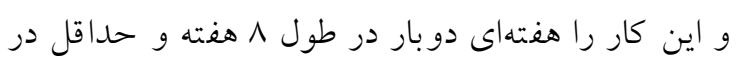

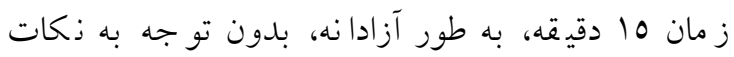
دستورى و غلط املايى در مكان آرام در منزل انجام دادند.

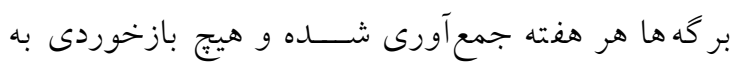

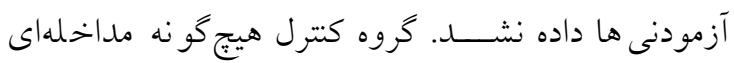
دريافت نكرد. بِ از خاتمه مداخله ابزار مذكور مجدداً

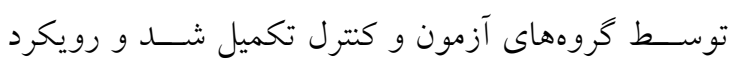

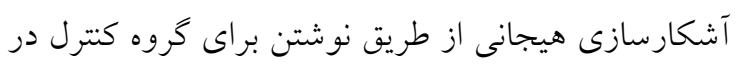

$$
\text { قالب لوح فشرده شرح داده شد. }
$$

اين مطالعه داراى مجوز كميته اخلاق از دانشـــاه علوم

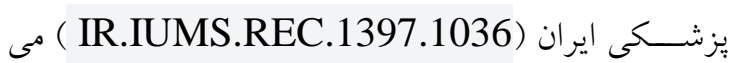

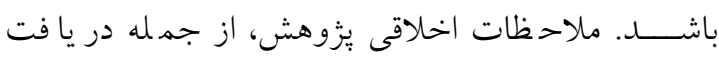

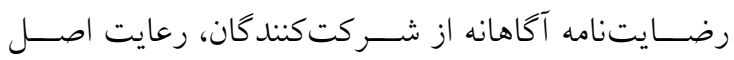

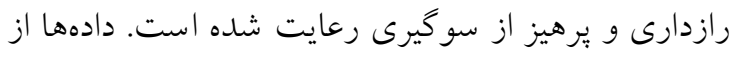

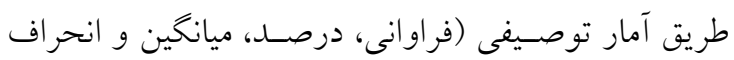

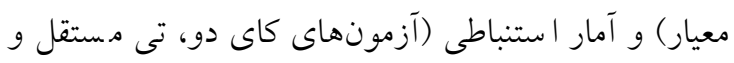

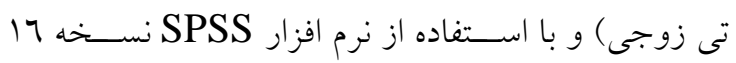
مورد تجزيه و تحليل قرار كرفت.

\section{يافتهها} مشـخصـات مادران شــركت كننده در مطالعه در جدول
خود مادر، داشتن فرزند مبتلا به اوتيسم در محدوده سنى

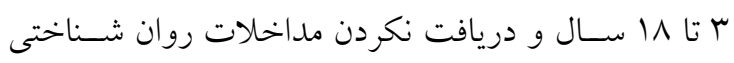

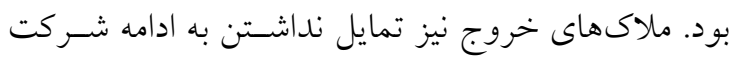

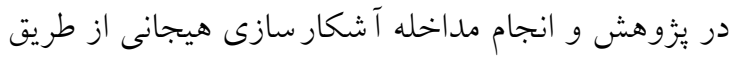

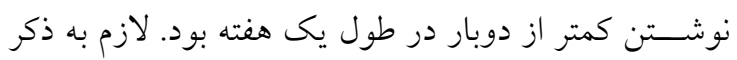

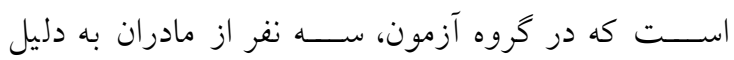

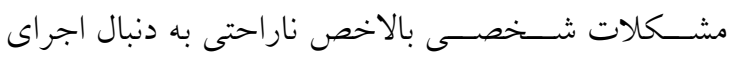

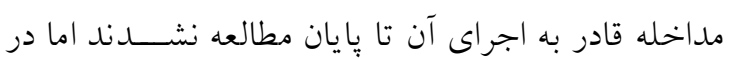
كروه كنترل ريزش نمونه اتفاق نيفتاد.

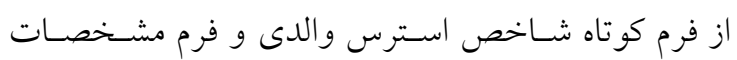
جمعيت شـناختى شـامل سـطح تحصسيلات، سـن، تعداد فرزند، وضعيت اقتصادى، سن كودك، سن شروع اختلال،

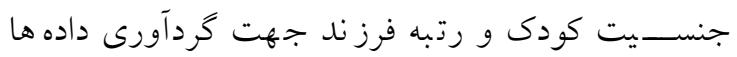

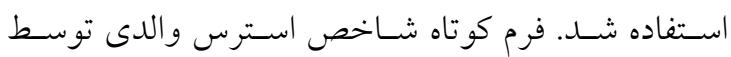
Abidin

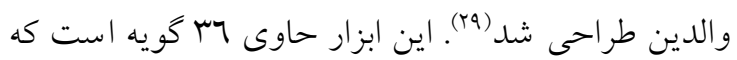
از ســه خرده مقياس آشـفتخى والدين، تعاملات ناكارآمد

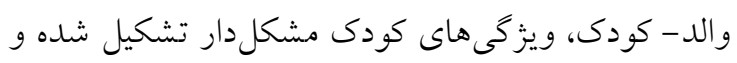

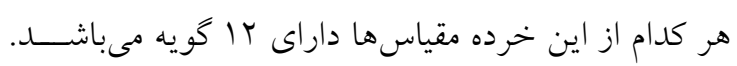

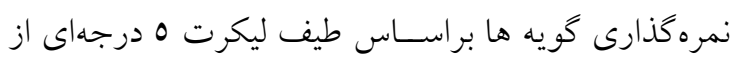

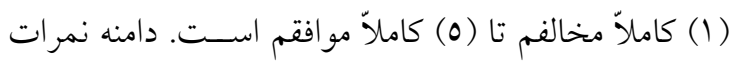

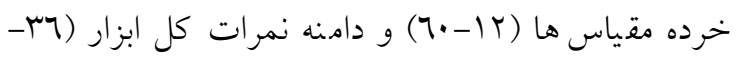

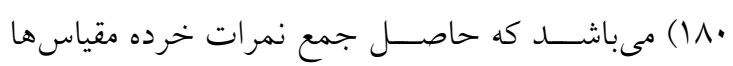

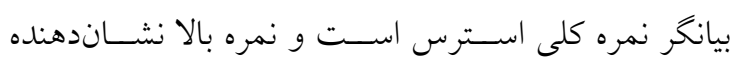

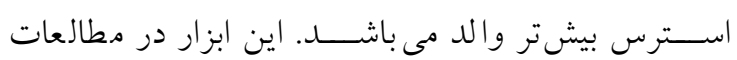

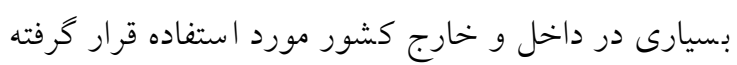

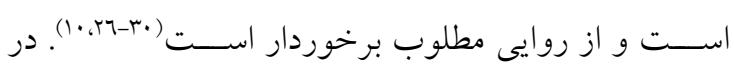

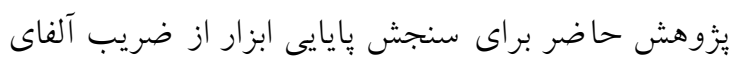

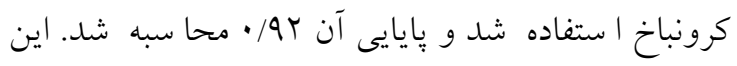

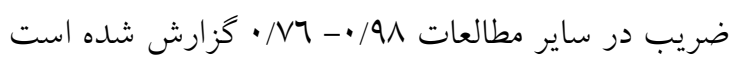

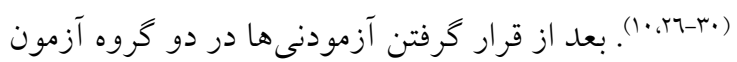
و كتترل، تمامى آزمودنىها ابزار اسـترس والدى رد را تكميل

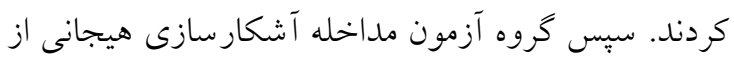

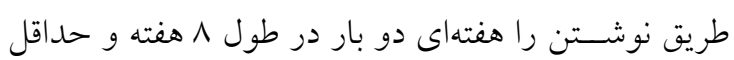


متغير جنس كودى با اسـترس والدى بررسى شــد و اين

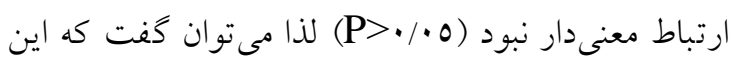
متغير مخدوشخر نبوده است.
شماره ا ارائه شده است. بر اساس اين جدول، دو كروه از مشخصات جمعيت شناختى همخن بودند (0) (P> P). از ميان مشخصات جمعيت شناختى، توزيع جنس كودى

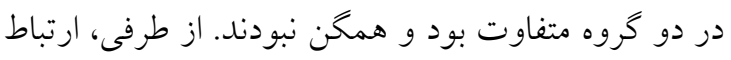

جدول شماره (: توزيع فراوانى مشخصات جمعيت شناختى مادران در دو كروه آزمون و كنترل و مقايسه آنها

\begin{tabular}{|c|c|c|c|c|c|c|}
\hline \multirow[t]{2}{*}{ نتايج همكنى دو كروه } & \multicolumn{2}{|c|}{ آزمون } & \multicolumn{2}{|c|}{ كنترل } & \multirow[t]{2}{*}{ 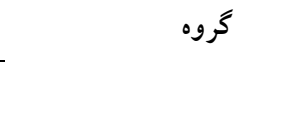 } & \multirow[b]{2}{*}{ متغير } \\
\hline & ل درصد & 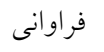 & درصد & 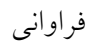 & & \\
\hline \multirow{2}{*}{$\begin{array}{l}\text { آزمون كاى دو } \\
\chi^{2}=. . .1\end{array}$} & $\mathrm{TW} / \mathrm{\Lambda}$ & Tr & $7 / 7$ & $r \varepsilon$ & ديبلم و يايينتر & سطح \\
\hline & $r M / r$ & 1. & $\mu_{1 / \varepsilon}$ & 11 & دانشكاهى & تحصيلات \\
\hline $\mathrm{p}=\cdot / 4 \wedge \vee \quad \mathrm{df}=1$ & $1 \ldots$ & rr & $1 \ldots$ & ro & جمع كل & \\
\hline آزمون تى مستقل & $r Y / 9$ & $v$ & $|V /|$ & 7 & $r \varepsilon-r$. & \\
\hline $\mathrm{df}=70, \mathrm{t}=\cdot / 7 \varepsilon \varepsilon$ & $\varepsilon\rceil / V$ & $1 \varepsilon$ & $r \varepsilon / r$ & ir & rq-ro & سن \\
\hline \multirow[t]{4}{*}{$\mathrm{p}=\cdot / \mathrm{or} r$} & $r / / \varepsilon$ & 11 & $\varepsilon N / 7$ & iv & $\varepsilon 0-\varepsilon$. & (سال) \\
\hline & $1 .$. & rt & $1 .$. & ro & جمع كل & \\
\hline & \multicolumn{2}{|c|}{$O r / 1 \pm \varepsilon r / r \varepsilon$} & \multicolumn{2}{|c|}{$0 \pi / 1 \cdot \pm r r / r \varepsilon$} & انحراف معيار 土 ميانكين & \\
\hline & \multicolumn{2}{|c|}{$\varepsilon Y / / \Lambda-T \varepsilon / 7\rceil$} & \multicolumn{2}{|c|}{$20 / 11-77 / 07$} & بيشينه - كمينه & \\
\hline \multirow{2}{*}{ 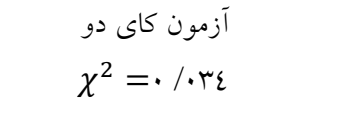 } & $09 / \varepsilon$ & 19 & ov/l & $r \cdot$ & يكى & \\
\hline & $\varepsilon \cdot / 7$ & ir & $\varepsilon T / q$ & 10 & دو & تعداد فرزند \\
\hline $\mathrm{p}=$ / / or $\quad \mathrm{df}=1$ & $1 .$. & rr & $1 \ldots$ & ro & جمع كل & \\
\hline آزمون كاى دو & $\cdot$ & $\cdot$ & . & $\cdot$ & ضعيف & \\
\hline$\chi^{2}=1 /$ rrq & $V N / 1$ & ro & $M / 7$ & $r_{1}$ & 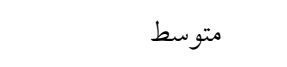 & وضعيت \\
\hline \multirow[t]{2}{*}{$\mathrm{p}=\cdot / \Gamma \varepsilon q$} & $r / 9$ & v & $11 / \varepsilon$ & $\varepsilon$ & 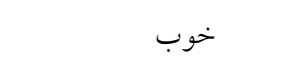 & |قتصادى \\
\hline & 1. & rr & $1 \ldots$ & ro & جمع كل & \\
\hline آزمون كاى دو & rN/I & 9 & $r r / 9$ & $\wedge$ & $\wedge-\vee$ & \\
\hline \multirow{2}{*}{$\begin{array}{c}\chi^{2}=\varepsilon / / V r \\
d f=r\end{array}$} & $\mathrm{rV} / 0$ & ir & $r V / 1$ & ir & $1 \cdot-9$ & سن كودى \\
\hline & rN/l & 9 & $\mid V / I$ & 7 & $|r-1|$ & (سال) \\
\hline \multirow[t]{2}{*}{$\mathrm{p}=\cdot / \pi \varepsilon r$} & $7 / r$ & r & $r r / 9$ & $\wedge$ & $\mid \varepsilon-14$ & \\
\hline & $1 \ldots$ & rr & $1 \ldots$ & ro & جمع كل & \\
\hline آزمون كاى دو & $70 / 7$ & rI & $1 \ldots$ & ro & پֶ, & جنسيت \\
\hline$\chi^{2}=1 \varepsilon / \sim 90$ & $r \varepsilon / \varepsilon$ & 11 & . & . & دختر & 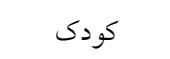 \\
\hline $\mathrm{p}<\cdot \cdots \cdot \quad \mathrm{df}=1$ & $1 .$. & rr & $1 .$. & ro & جمع كل & \\
\hline آزمون كاى دو & $V 1 / 9$ & $r \mu$ & $V \varepsilon / r$ & r & اول & \\
\hline$\chi^{2}=\cdot / \cdot \varepsilon 9$ & TN/I & 9 & ro/v & 9 & 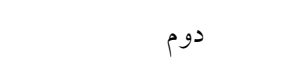 & 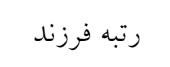 \\
\hline $\mathrm{p}=\cdot / \wedge r \varepsilon$ & $1 \ldots$ & rr & $1 .$. & ro & جمع كل & \\
\hline آزمون كاى دو & $\mathrm{rV} / 0$ & ir & $\varepsilon r / 9$ & 10 & دو & سن شروع \\
\hline$\chi^{2}=. / 199$ & $T r / 0$ & $r \cdot$ & ov/l & $r \cdot$ & سه & اختلال (سال) \\
\hline $\mathrm{p}=\cdot / 770 \quad \mathrm{df}=1$ & $1 \ldots$ & rr & $1 .$. & ro & جمع كل & \\
\hline
\end{tabular}


به كُوه كتترل به صـورت معنى دارى كمتر اما نمرات

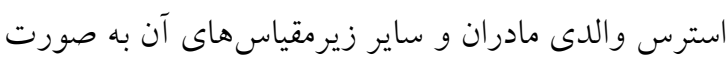

معنى دارى بيشتر بود (جدول شماره Y).
اختلاف آمارى معنى دارى وجود نداشـــت اما

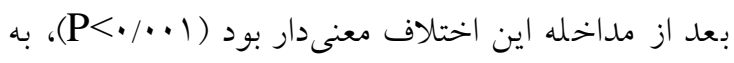

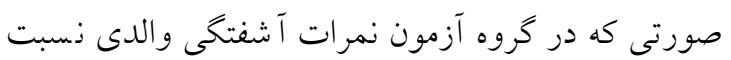

جدول شماره r: مقايسه استرس والدى و زيرمقياسهاى آن در دو تروه كنترل و آزمون در زمانهاى قبل و بعد از مداخله

\begin{tabular}{|c|c|c|c|c|c|c|}
\hline \multirow{2}{*}{ آزمون تى } & \multicolumn{2}{|c|}{ بعد از مداخله } & \multirow{2}{*}{ آزمون تى } & \multicolumn{2}{|c|}{ قبل از مداخله } & كروه \\
\hline & آزمون & كتترل & & آزمون & كترل & 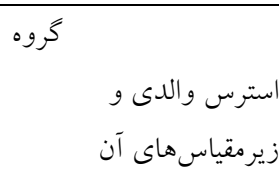 \\
\hline $\begin{array}{l}\mathrm{t}=\Lambda /|r| \\
\mathbf{p}<\cdot / \cdot \cdot 1 \\
\mathrm{df}=0 / / 97\end{array}$ & $r q / \cdot 7 \pm 7 / .1$ & $\varepsilon Y / \cdot 0 \pm 7 / q \Lambda$ & $\begin{array}{c}\mathrm{t}=\cdot / \Lambda \Lambda \mid \\
\mathrm{p}=\cdot / \Lambda \Lambda \mid \\
\mathrm{df}=71 / 11\end{array}$ & $\varepsilon 1 / \Gamma) \pm V / \cdot V$ & $\{1 / 0 V \pm 7 / 97$ & 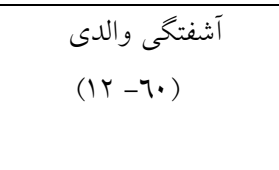 \\
\hline $\begin{array}{c}\mathrm{t}=-\mathrm{V} / \cdot \mathrm{V} \varepsilon \\
\mathrm{p}<\cdot / \cdot \cdot \cdot 1 \\
\mathrm{df}=70\end{array}$ & $\varepsilon q / T \vee \pm 0 / 1 \varepsilon$ & $r q / \cdot 0 \pm T / 7 r$ & $\begin{array}{l}\mathrm{t}=\cdot / 97 \pi \\
\mathrm{p}=\cdot / 97 \pi \\
\mathrm{df}=70\end{array}$ & $r N \cdot 9 \pm 0 / N r$ & $r N \cdot r \pm O / N$. & كعاملات ناكارآمد والد- \\
\hline $\begin{array}{l}t=-0 / \cdot \varepsilon \\
p<\cdot / . \cdot 1 \\
d f=70\end{array}$ & $0 . / \pi \varepsilon \pm T / \varepsilon V$ & $\varepsilon \cdot / \Lambda \cdot \pm \Lambda / V \varepsilon$ & $\begin{array}{l}\mathrm{t}=\cdot / \wedge 0 \\
\mathrm{p}=\cdot / \wedge 0 \\
\mathrm{df}=\wedge 7\end{array}$ & $r q / 2 \cdot \pm V / 97$ & $r q / v v \pm v / v 7$ & ويزَّى هاى كودك مشكل \\
\hline $\begin{array}{l}\mathrm{t}=-1 / 7 \mathrm{~V} 7 \\
\mathbf{p}=\cdot / \cdot \varepsilon \mathrm{V} \\
\mathrm{df}=70\end{array}$ & $\mid r N / V A \pm I Y / T q$ & $1 T r / 20 \pm 1 V / 70$ & $\begin{array}{l}\mathrm{t}=\cdot / \wedge V I \\
\mathrm{p}=\cdot / \wedge V \mid \\
\mathrm{df}=\wedge \mathrm{T}\end{array}$ & $\| N / \Lambda| \pm| \varepsilon / \cdot 1$ & $119 / r V \pm 1 r / 9 r$ & استرس والدى \\
\hline
\end{tabular}

نمرات استرس والدى مادران و ساير زيرمقياسهاى آن به

نتايج آزمون تى زوجى در جدول شــماره ب نشـــان داد

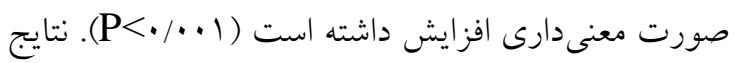

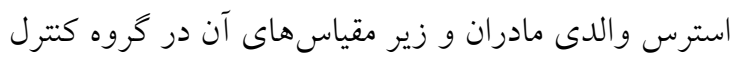

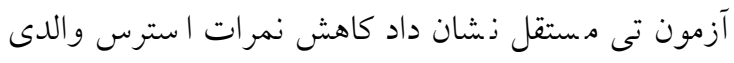

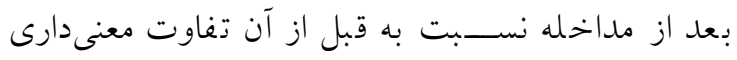

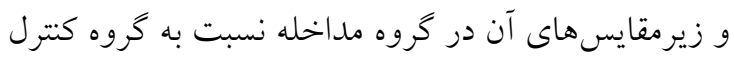

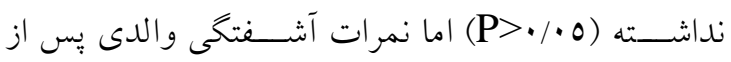

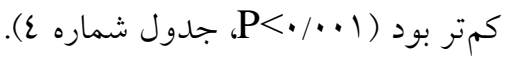

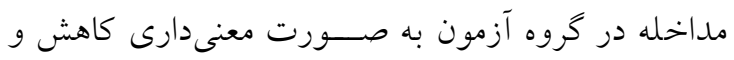

جدول شماره ب: مقايسه درون تروهى استرس والدى و زيرمقياس هاى آن قبل و يس از مداخله در دو كروه آزمون و كنترل

\begin{tabular}{|c|c|c|c|c|c|c|}
\hline \multirow[t]{3}{*}{ آزمون تى زوجى } & \multicolumn{2}{|c|}{ آزمون } & \multirow{3}{*}{ زآزمون تى } & \multicolumn{2}{|c|}{ كنترل } & \multirow[t]{2}{*}{ كروه } \\
\hline & بعد از مداخله & قبل از مداخله & & بعد از مداخله & قبل از مداخله & \\
\hline & & & & & & و زيرمقياسهاى آن \\
\hline$t=r 0 / 011$ & $r q / \cdot 7 \pm 7 / \cdot 1$ & $\varepsilon 1 / r) \pm V / \cdot V$ & $t=-1 / 7 \cdot V$ & $\sum r / \bullet 0 \pm T / q \Lambda$ & $\{1 / 0 V \pm 7 / 97$ & آشفتىى والدى \\
\hline $\mathrm{p}<\cdot / \cdot \cdot 1$ & & & $\mathrm{p}=\cdot / 1 \mathrm{IV}$ & & & $\left(\mid r-T_{\bullet}\right)$ \\
\hline $\mathrm{df}=\mathrm{rl}_{\mathrm{I}}$ & & & $d f=r \varepsilon$ & & & \\
\hline$t=-20 / 79 r$ & $\varepsilon q / r v \pm 0 / 1 \varepsilon$ & $r_{N} \cdot 9 \pm O N N^{T}$ & $t=-1 / A Y T$ & $r q / .0 \pm T / 7 r$ & $r_{N /} \cdot r \pm O / N$. & تعاملات ناكارآمد \\
\hline
\end{tabular}




\begin{tabular}{|c|c|c|c|c|c|c|}
\hline $\begin{array}{c}\mathrm{p}<\bullet / \cdots+ \\
\mathrm{df}=\mathrm{ml}^{-}\end{array}$ & & & $\begin{array}{l}\mathrm{p}=\cdot / \cdot \tau \mu \\
\mathrm{df}=r \varepsilon\end{array}$ & & & 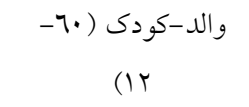 \\
\hline$t=-r 0 / r u$ & $0 . / \mu \varepsilon \pm \tau / \varepsilon V$ & $r q / \varepsilon \cdot \pm v / 97$ & $\mathrm{t}=-1 / \wedge \mathrm{rV}$ & $\varepsilon \cdot / \Lambda \pm \Lambda / \vee \varepsilon$ & $\mathrm{rq} / \mathrm{VV} \pm \mathrm{V} / \mathrm{V} \mathrm{T}$ & ويزگى هاى كودى \\
\hline $\mathrm{p}<\bullet / \cdots+$ & & & $\mathrm{p}=\cdot / \cdot \vee \mathrm{o}$ & & & مشكل دار (•T- r I) \\
\hline $\mathrm{df}=\mathrm{rl}_{1}$ & & & $d f=r \varepsilon$ & & & \\
\hline$t=-10 / .00$ & $|r N / V \Lambda \pm| r / r q$ & $\| N / \Lambda| \pm| \varepsilon / \cdot 1$ & $\mathrm{t}=-1 / 910$ & $\mid r r / 20 \pm 1 V / 70$ & $119 / r V \pm 1 r / 9 r$ & استرس والدى (•^||- \\
\hline $\mathrm{p}<\bullet / \cdots+$ & & & $\mathrm{p}=\cdot 1.00$ & & & (ry \\
\hline$d f=r_{1}$ & & & $\mathrm{df}=r \varepsilon$ & & & \\
\hline
\end{tabular}

جدول شماره ع: مقايسه تغييرات سطح استرس مادران و زير مقياسهاى آن در دو كَروه كنترل و آزمون

\begin{tabular}{|c|c|c|c|c|c|}
\hline \multirow{3}{*}{$\begin{array}{c}\text { نتايج آزمون تى مستقل } \\
\text { df=70 }\end{array}$} & \multicolumn{3}{|c|}{ كنترل } & آزمون & \multirow{2}{*}{ 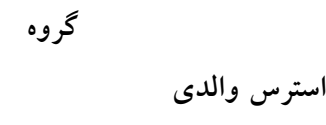 } \\
\hline & انحراف معيار & ميانخين اختلاف قبل و & انحر اف معيار & ميانكين اختلاف & \\
\hline & اختلاف ها & بعد از مداخله & اختلاف ها & قبل و بعد از م هفته & و زير مقياسهاى آن \\
\hline $\mathrm{t}=-\mathrm{rV} / \wedge \mathrm{V}$ & $1 / 90$ & $\mid r / r O$ & $1 / V \wedge$ & $-\cdot / \varepsilon \wedge$ & آشفتگى والدى (•ج-TI) \\
\hline \multicolumn{6}{|l|}{$\mathrm{p}<\bullet / \cdots$} \\
\hline $\mathrm{t}=17 / \wedge 7$ & $1 / \pi q$ & $-11 / r \Lambda$ & $r / 17$ & $-1 / \cdot r$ & تعاملات ناكارآمد والد- فرزند \\
\hline $\mathrm{p}<\bullet / \cdots$ & & & & & $\left.\mid Y-T^{\prime}\right)$ \\
\hline $\mathrm{t}=|\mu / \Lambda|$ & $T / \varepsilon \varepsilon$ & $-1 \cdot / 9 r$ & $r / \mu$ & $-1 / \cdot r$ & ويزگگىهاى كودى مشكلدار \\
\hline $\mathrm{p}<\bullet / \cdots$ & & & & & $(\mid Y-7 \cdot)$ \\
\hline$t=r / 9 \varepsilon$ & $\mathrm{r} / \mathrm{V} \varepsilon$ & $-9 / 97$ & $9 / 19$ & $-r / \cdot \wedge$ & استرس والدى (•^|^-M) \\
\hline $\mathrm{p}<\bullet / \cdots$ & & & & & \\
\hline
\end{tabular}

بر ا سترس روان شناختى و ا سترس فيزيولوزيك والدين

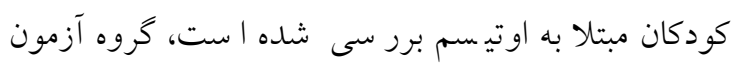

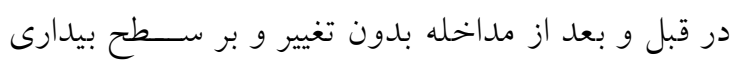
كورتيزول كه زشانخر استرس فيزولوزيك مطالعه بود تأثير مثبت داشته است. از آن جا كه عناوين نوشتارى در مطالعه ذكر شده براى آ شكار سازى هيجانى در زمينه مراقبت از كودى اوتي سم تخصصيص نيافته بود، نتيجه به د ست آمله،

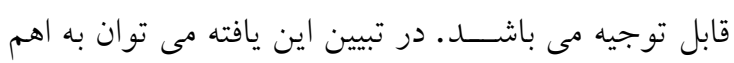

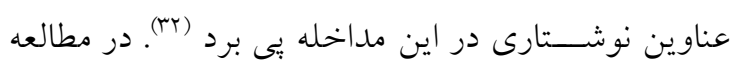
ديخرى نيز كه به منظور تعيين اثر بخشـى ســهـ مداخلهى

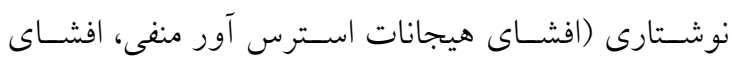
هيجانات مثبت و نوشتن در مورد موضوع خنتى) بر علائم

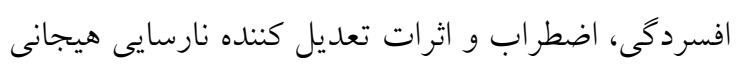
در مراقبان غير رسـمى يرداخته شــده اسـت نتايج بيانكر فقدان وجود اختلاف معنىدار آ مارى در قبل و بـعد از

\section{بحث و نتيجه كيرى}

آشـــكارســـازى هيجانى از طريق نوشـــن باعث افزايش

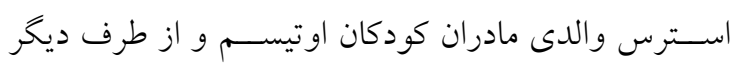
باعث بهبودى در زير مقياس آشفتخى والدى در مقايسه با

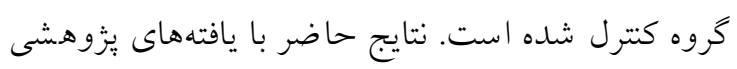
كه به بررسسى اثر بخشسى آشـكارسـازى هيجانى از طريق نوشـتن بر سـطح اسـترس مادران، براى مادرانى كه فرزند داراى رفتارهاى اجتماعى مخرب دارند، تا حدودى همسو است. طبق نتايج مطالعهاى كه در اردن انجام شد، استرس والدى در گروه آزمون بعد از اجراى مداخله افزايش يافته است اما با اجراى مجدد مداخله تو سط كروه كنترل نتيجه

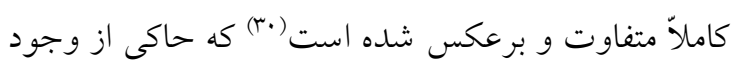
نتايج متناقض در جّخونخى اثر بخشى مداخله آشكارسازى

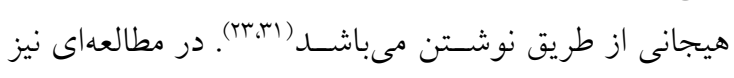
كه در ايالات متحده امريكا انجام شد (·) تأثير اين مداخله 
والدى نيز تأييد شــــه اســت به كونهايى كه زير مقياس كودى دشـوار ارتباط قوى با اسـترس كلى والدى و ييش نيش

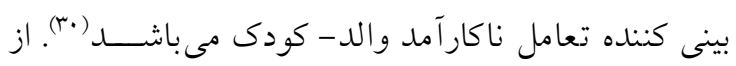
طرفى در مطالعه ديخرى كه در ايالات متحده امريكا انجام

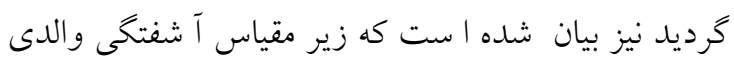

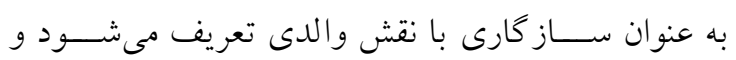

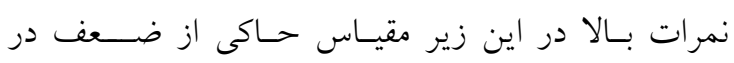

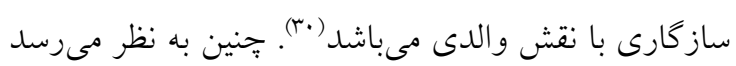

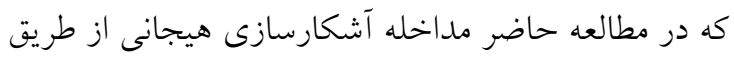
نو شتن منجر به افزايش سازكارى در نقش بذ بذيرى مادران

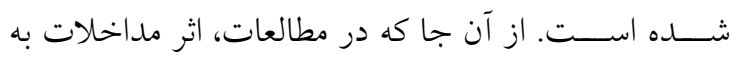

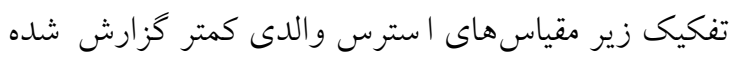

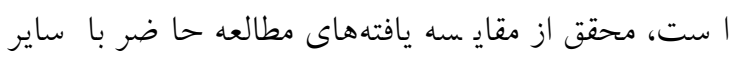

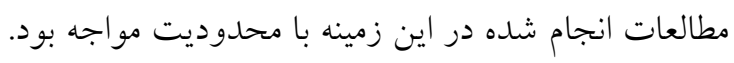
در هر حال، يافته هاى اين بخش از مطالعه، نيازمند تمركز بيشتر محققان در اين حيطه باشد.

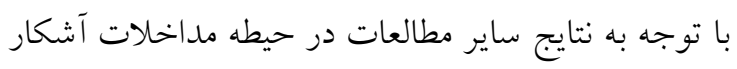

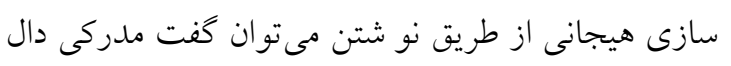

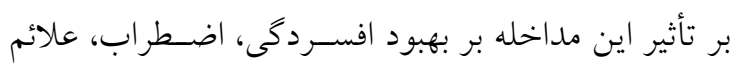
جسمى يا بار مراقبت وجود ندارد و ارزيابى يافتهها نتايج

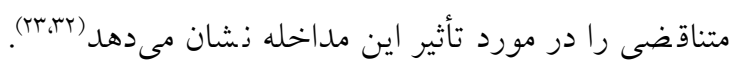

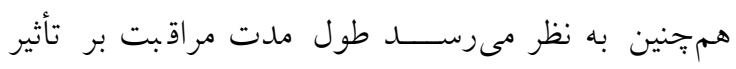

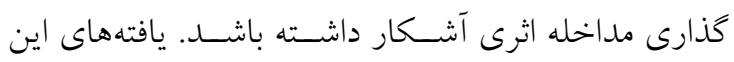

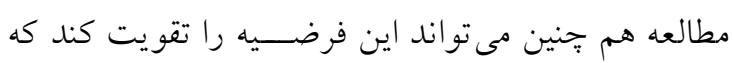

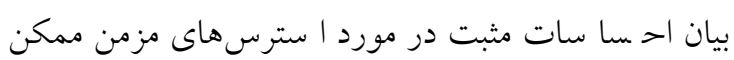

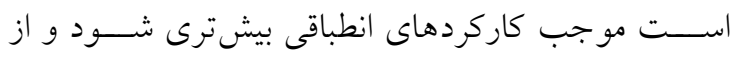

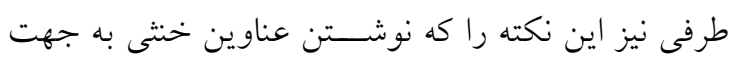

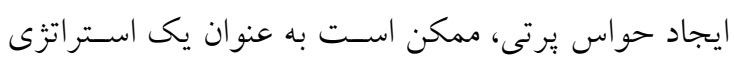

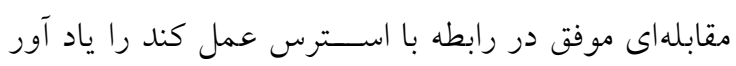

از محدوديتهاى يزّوهش حاضر مىتوان به عدم مصصاحبه

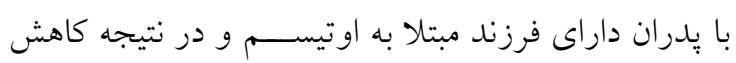

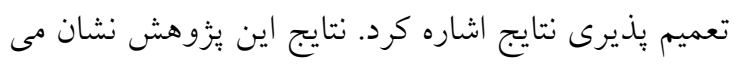

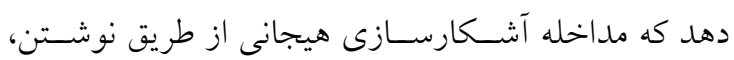

مداخله در هر سـه كروه بود. اين محققان نشـان دادند كه

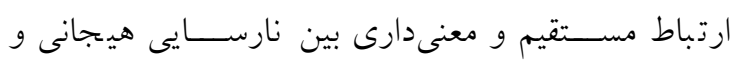
افسردگى و اضطراب در دو گروهى كه به نو شتن عناوين

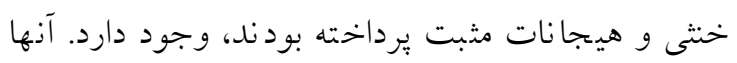

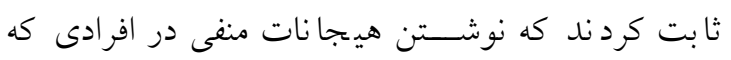

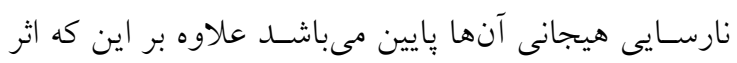

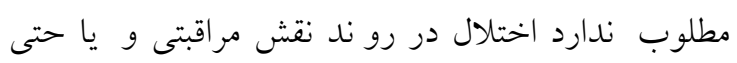

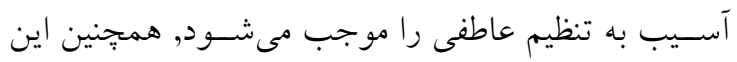

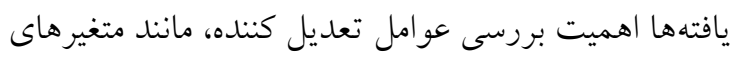

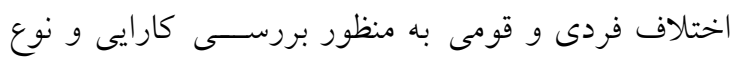
مداخلات آشكارسازى هيجانى را خاطر نشان مى كند (rr).

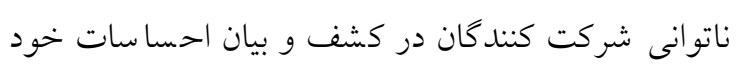

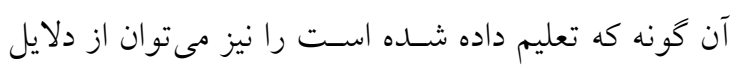
شكست مداخله آشكارسازى هيجانى از طريق نوشتن (Tr)،

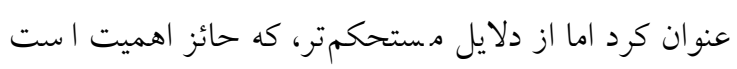

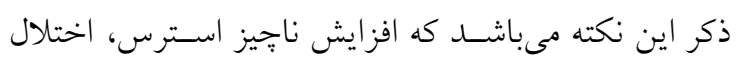

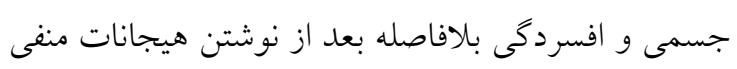

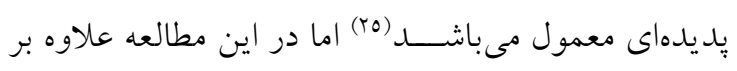

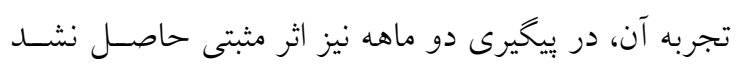

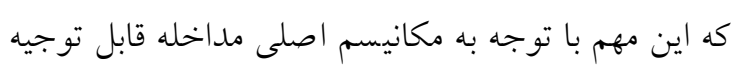

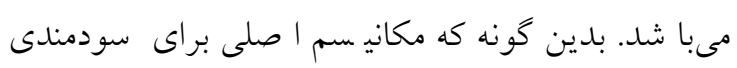

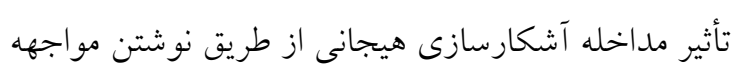

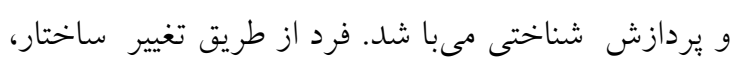

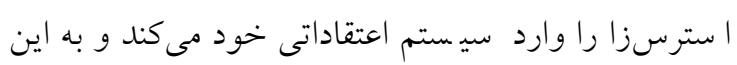

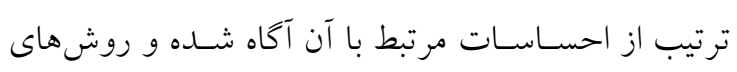

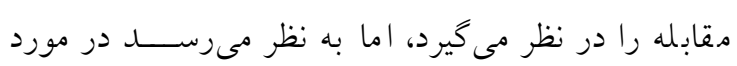

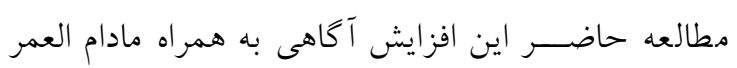

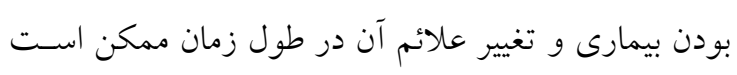

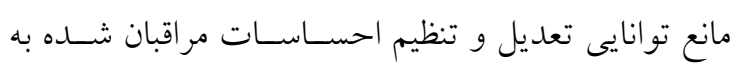

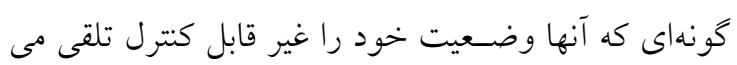

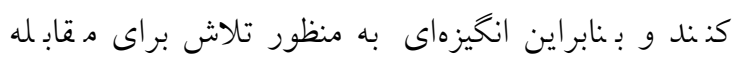

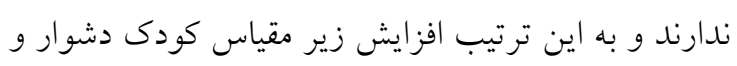

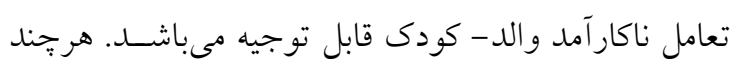

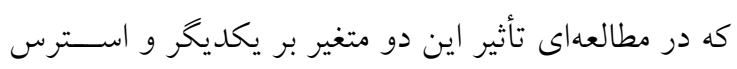




$$
\begin{aligned}
& \text { استفاده نمايند تا امكان مقايسهاى بيشتر فراهم گردد. } \\
& \text { تعارض منافع: هيج گونه تعارض منافع از سوى نويسندگان }
\end{aligned}
$$

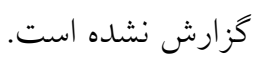

$$
\begin{aligned}
& \text { تقدير و تشكر }
\end{aligned}
$$

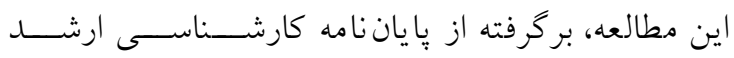

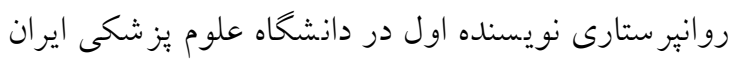

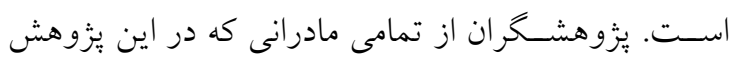

$$
\begin{aligned}
& \text { مشاركت نمودند، سياسخزارى مىنمايند. }
\end{aligned}
$$

\section{References}

1. Lyall K, Croen L, Daniels J, Fallin MD, Ladd-Acosta C, Lee BK, Park BY, Snyder NW, Schendel $\mathrm{D}$, Volk H, Windham GC. The changing epidemiology of autism spectrum disorders. Annual review of public health. 2017;38:81-102.

2. Liu J, Yao L, Zhang W, Xiao Y, Liu L, Gao X, Shah C, Li S, Tao B, Gong Q, Lui S. Gray matter abnormalities in pediatric autism spectrum disorder: a meta-analysis with signed differential mapping. Eur Child Adol Psych. 2017;26(8):933-45.

3. Guo X, Duan X, Long Z, Chen H, Wang Y, Zheng J, Zhang Y, Li R, Chen H. Decreased amygdala functional connectivity in adolescents with autism: a resting-state fMRI study. Psych Res: Neuro. 2016;257:47-56.

4. Baxter AJ, Brugha TS, Erskine HE, Scheurer RW, Vos T, Scott JG. The epidemiology and global burden of autism spectrum disorders. Psychol Medic. 2015;45(3):601-13.

5. Porter N, Loveland KA. An integrative review of parenting stress in mothers of children with autism in Japan. Int J Disab, Develop Educ. 2019;66(3):249-72.

6. Lord C, Elsabbagh M, Baird G, Veenstra-Vanderweele J. Autism spectrum disorder. The Lancet. 2018;392(10146):508-20.

7. Shepherd D, Landon J, Taylor S, Goedeke S. Coping and care-related stress in parents of a child with autism spectrum disorder. Anxiety, Stress, \& Coping. 2018;31(3):277-90.

8. Rogge N, Janssen J. The economic costs of autism spectrum disorder: A literature review. J Autism Develop Disord. 2019;49(7):2873-900.

9. Al-Oran HM, AL-Sagarat AY. Parenting stress of children with autistic disorder. Open Access Library Journal. 2016;3(7):1-10.

10. Da Paz NS, Wallander JL, Tiemensma J. Effects of written disclosure on psychophysiological stress among parents of children with autism: A randomized controlled pilot study. Res Autism Spectrum Disord. 2018;53:7-17.

11. Catalano D, Holloway L, Mpofu E. Mental health interventions for parent carers of children with autistic spectrum disorder: Practice guidelines from a critical interpretive synthesis (CIS) systematic review. Int J Environm Res Public Health. 2018;15(2):341.

12. Sim A, Cordier R, Vaz S, Falkmer T. Relationship satisfaction in couples raising a child with autism spectrum disorder: A systematic review of the literature. Res Autism Spectrum Disord. 2016;31:3052.

13. Barroso NE, Mendez L, Graziano PA, Bagner DM. Parenting stress through the lens of different clinical groups: A systematic review \& meta-analysis. J Abnormal Child Psychol. 2018;46(3):44961.

14. Miranda A, Mira A, Berenguer C, Rosello B, Baixauli I. Parenting stress in mothers of children with autism without intellectual disability. Mediation of behavioral problems and coping strategies. Frontiers in psychology. 2019;10:464. 
15. Giovagnoli G, Postorino V, Fatta LM, Sanges V, De Peppo L, Vassena L, De Rose P, Vicari S, Mazzone L. Behavioral and emotional profile and parental stress in preschool children with autism spectrum disorder. Res developm disabil. 2015;45:411-21.

16. Zaidman-Zait A, Mirenda P, Duku E, Vaillancourt T, Smith IM, Szatmari P, Bryson S, Fombonne $\mathrm{E}$, Volden J, Waddell C, Zwaigenbaum L. Impact of personal and social resources on parenting stress in mothers of children with autism spectrum disorder. Autism. 2017;21(2):155-66.

17. Foody C, James JE, Leader G. Parenting stress, salivary biomarkers, and ambulatory blood pressure: a comparison between mothers and fathers of children with autism spectrum disorders. $J$ autism develop disord. 2015;45(4):1084-95.

18. Frye L. Fathers' experience with autism spectrum disorder: Nursing implications. Journal of Pediatric Health Care. 2016;30(5):453-63.

19. Akram B, Batool M, Bibi S. Burden of care and suicidal ideation among mothers of children with Autism spectrum disorder: perceived social support as a moderator. JPMA. 2019;69(504).

20. Da Paz NS, Wallander JL. Interventions that target improvements in mental health for parents of children with autism spectrum disorders: A narrative review. Clin Psychol Rev. 2017;51:1-4.

21. Dababnah S, Parish SL. A comprehensive literature review of randomized controlled trials for parents of young children with autism spectrum disorder. $J$ evidence-informed social work. 2016;13(3):277-92.

22. Lunsky Y, Fung K, Lake J, Steel L, Bryce K. Evaluation of acceptance and commitment therapy (ACT) for mothers of children and youth with autism Spectrum Disorder. Mindfulness. 2018;9(4):1110-6.

23. Riddle JP, Smith HE, Jones CJ. Does written emotional disclosure improve the psychological and physical health of caregivers? A systematic review and meta-analysis. Behav Res Therapy. 2016;80:23-32.

24. Craig F, Operto FF, De Giacomo A, Margari L, Frolli A, Conson M, Ivagnes S, Monaco M, Margari F. Parenting stress among parents of children with neurodevelopmental disorders. Psychiatry research. 2016;242:121-9.

25. Acar D, Dirik G. A Current Paradigm: Written Emotional Disclosure. Current Approaches in Psychiatry/Psikiyatride Guncel Yaklasimlar. 2019;11(5).

26. Farahani H, Azad SA, Sahebalzamani M. Investigating the effect of maternal narrative writing on depression, anxiety and stress in pediatric stem cell transplantation. NeuroQuantology. 2017;15(4):56-64. [Persian]

27. Kadivar M, Seyedfatemi N, Akbari N, Haghani H. The effect of narrative writing on maternal stress in neonatal intensive care settings. The Journal of Maternal-Fetal \& Neonatal Medicine. 2015;28(8):938-43.

28. Zauszniewski JA, Musil CM, Burant CJ, Au TY. Resourcefulness training for grandmothers: Preliminary evidence of effectiveness. Research in nursing \& health. 2014;37(1):42-52.

29. Abidin RR. Parenting Stress Index (PSI) manual. $3^{\text {th }}$ ed. Charlottesville, VA: Pediatric Psychology Press.1995.

30. Whitney RV, Smith G. Emotional disclosure through journal writing: Telehealth intervention for maternal stress and mother-child relationships. J Autism Developm Disord. 2015;45(11):3735-45.

31. Dardas LA, Ahmad MM. Psychometric properties of the P arenting S tress I ndex with parents of children with autistic disorder. J Intell Disab Res. 2014;58(6):560-71.

32. Leng YN, Zhang M, Liu TT. Effects of Written Emotional Disclosure on Burden, Trauma Symptoms and Health Status in Primary Caregivers of The Patient: A meta-analysis [J]. Medical Data Mining. 2019;2(3):126-33.

33. Ashley L, O'Connor DB, Jones F. Effects of emotional disclosure in caregivers: Moderating role of alexithymia. Stress and Health. 2011;27(5):376-87. 